\title{
KEKUDUSAN HIDUP MENURUT 1TESALONIKA 4:1-8 RELEVANSINYA TERHADAP PEMAHAMAN PEMUDA DI GKAI SUNTER
}

\section{Enny Irawati*}

\author{
Dosen di Sekolah Tinggi Teologi Biblika Jakarta
}

Diterima: 31 Januari 2020; Disetujui: 1 Maret 2020; Dipublikasikan: 6 April 2020

\begin{abstract}
Abstrak
Penelitian ini dimaksudkan untuk menganalisis secara mendalam dan obyektif pemahaman pemuda GKAI Sunter tentang kekudusan menurut 1Tesalonika 4:1-8). Penelitian ini menggunakan metode penelitian kualitatif analisis taksonomi, dengan menggunakan penelitian penafsiran Alkitab secara induktif didasarkan pada paradigma naturalistic. Data dikumpulkan melalui observasi partisipan menggunakan wawancara tertulis berdasarkan kekudusan menurut 1Tesalonika 4:1-8. Pertanyaan yang digunakan berdasarkan analisa dengan tiga sub focus (1) Hidup yang berkenan kepada Allah, (2) Hidup dalam kekudusan, (3) Hidup melakukan kehendak Tuhan. Sampel yang digunakan berjumlah 7 pemuda dari usia 16-23 tahun, jenis kelamin pria dan wanita. Hasil penelitian menunjukkan bahwa pemuda GKAI Sunter memiliki pemahaman yang baik tentang kekudusan. Pemahaman yang paling tinggi bahwa dalam pernikahan Kristen bersifat monogami dan tidak boleh ada perceraian, dilanjutkan dengan pemahaman bahwa menjaga kekudusan berarti tidak boleh melakukan seks di luar penikahan dan yang paling rendah adalah pemahaman tentang jenis percabulan yang harus dijauhi yaitu pembunuhan dan kata-kata kotor.
\end{abstract}

Kata Kunci: Kekudusan, Pemahaman, Pemuda.

\begin{abstract}
This research is intended to analyze in depth and objectively the understanding of GKAI Sunter youth about holiness according to 1 Thessalonians 4: 1-8). This study uses qualitative research methods in taxonomic analysis, using inductive interpretation of biblical research based on the naturalistic paradigm. Data was collected through participant observation using holiness based written interviews according to 1 Thessalonians 4: 1-8. The questions used are based on an analysis with three sub focus (1) Life that pleases God, (2) Life in holiness, (3) Life doing God's will. The samples used were 7 young men from the age of 16-23 years, male and female sex. The results showed that the youth of GKAI Sunter had a good understanding of holiness. The highest understanding that in Christian marriage is monogamous and there should be no divorce, continued with the understanding that maintaining holiness means not having sex outside marriage and the lowest is an understanding of the type of fornication that must be shunned, namely murder and obscenities.
\end{abstract}

Keywords: Holiness, Understanding, Youth.

How to Cite: Dr. Enny Irawati, M.Th. (2020). Kekudusan Menurut 1Tesalonika 4:1-8 Relevansinya Terhadap Pemahaman Pemuda GKAI Sunter. Jurnal Teologi Biblika, $5(1): 3-12$.

*Corresponding author:

ISSN 2355-1704 (Print)

E-mail: etrifena@gmail.com 


\section{PENDAHULUAN}

Kekudusan merupakan bagian yang penting dalam kehidupan orang percaya, seperti yang tertulis dalam 1Petrus. 1:16 "kuduslah kamu sebab Aku kudus." Hidup dalam kekudusan memungkinkan orang percaya untuk memiliki persekutuan yang erat dengan Tuhan Allah.

Di dalam kekudusan yang sejati, manusia dapat hidup dan bersekutu dengan Tuhan Allah, ia hidup di dalam kekudusan Allah. Manusia harus memiliki sikap hati yang benar di hadapan Allah tanpa harus merasa takut dan bersalah. Di dalam kekudusan yang sejati ini manusia sebenarnya menjalankan fungsi seorang imam. ${ }^{1}$

Sudah banyak berita yang beredar baik di televisi, koran, artikel-artikel, youtube dan media sosial lainnya yang menyatakan bahwa banyak anak muda yang menggunakan narkoba, merokok, berpesta pora dan terlibat dalam pergaulan bebas dan seks bebas yang pada akhirnya hamil di luar nikah. Oleh sebab itu perlu adanya pemahaman yang benar tentang menjaga kekudusan yang dimulai sejak usia dini agar tidak terjadi di kemudian hari hal-hal tersebut di atas.

Mengutip dari Marthin Luther, seorang Teolog yang memiliki pandangan bahwa "kekudusan merupakan suatu tindakan untuk mengucap syukur kepada Allah karena telah mengampuni dan membenarkan kita demi Kristus hanya melalui iman."2

Menuliskan pemikiran Calvinisme tentang kekudusan bahwa "manusia yang sudah diampuni dan dibenarkan karena Iman, harus berusaha sedapat mungkin menjaga dan mengupayakan kekudusan hidupnya. Supaya bertumbuh dalam kasih karunia, dan menyempurnakan kekudusan dengan takut akan Allah". 3

Menuliskan pemikiran Jhon Wesley yang mengajarkan bahwa "kesucian adalah keinginan hidup saleh yang sejati merupakan satu kekuatan rohani untuk mengasihi Allah dan manusia tanpa ini semua maka Agama adalah dangkal dan kosong."

Dari uraian di atas dapat diambil kesimpulan bahwa orang percaya yang mengasihi Tuhan wajib menjaga kekudusan hidupnya dan menjauhkan diri dari halhal yang cemar.

Dalam lingkungan yang majemuk tidak dapat dipungkiri bahwa pemudapemudi GKAI Sunter memiliki pemahaman yang berbeda tentang kekudusan hidup. Disinilah diperlukan adanya pemahaman teologis yang benar tentang kekudusan hidup.

Berdasarkan latar belakang di atas, Peneliti bermaksud untuk melakukan penelitian literatur eksegesa yang bertujuan untuk menemukan makna teologis tentang kekudusan menurut 1Tesalonika 4:1-8 dan pemahaman pemuda GKAI Sunter tentang kekudusan hidup.

\footnotetext{
${ }^{1}$ J. Wesley Brill, Doa-Doa dalam Perjanjian Baru (Bandung: Penerbit Kalam Hidup), 23.

${ }^{2}$ Alister E. Mc Grath, Sejarah Pemikiran Reformasi (Jakarta: BPK. Gunung Mulia, 2000), 129-130.

${ }^{3}$ Jan S. Ariotang, Berbagai Aliran di Dalam dan Disekitar Gereja (Jakarta:BPK. Gunung Mulia, 1995), 65.

${ }^{4}$ Mecroskey, Robert D, Theologia Sistematika dari Sudut Pandang Wesley-Arminion (Yogyakarta: Khabar Kekudusan, 2004), 105
} 


\section{METODE PENELITIAN}

Pendekatan penelitian ini adalah pendekatan penelitian kualitatif analisis taksonomi, dengan menggunakan penelitian penafsiran Alkitab secara induktif (eksegesa). Penafsiran Alkitab adalah suatu penelitian biblika yang bertujuan mengeluarkan makna teks. ${ }^{5}$ Untuk mengarahkan perancangan dan pelaksanaan penelitian ini, maka paradigma penelitian adalah paradigma naturalistic. Metode penelitian naturalistic karena penelitian yang dilakukan pada kondisi yang alamiah, sumber data ialah situasi yang wajar atau "natural setting." Peneliti mengumpulkan data berdasarkan observasi situasi yang wajar, sebagaimana adanya, tanpa dipengaruhi dengan sengaja. Peneliti yang memasuki lapangan berhubungan langsung dengan situasi dan orang yang diselidikinya. Paradigm naturalistic atau paradigma alamiah adalah berdasarkan pada filsafat fenomenologis. Filsafat fenomenologis ini kemudian berkembang dan salah satu perekembangannya diantaranya ialah menjadi metode, yaitu metode fenomenologis. ${ }^{6}$

Teknik pengumpulan data dipergunakan peneliti adalah: Pertama, adalah melakukan tafsir teks Alkitab dengan melakukan pekerjaan eksegese. Kedua, adalah wawancara dengan informan. Ketiga, membuat Analisa hasil penelitian. Wawancara dilakukan dengan menggunakan pedoman tertulis yang telah disiapkan sebelumnya, yang berisi sejumlah pertanyaan yang akan diajukan kepada informan. Semua kajian dalam penelitian ini adalah pemuda GKAI Sunter Jakarta. ${ }^{7}$

Penelitian ini dilakukan di GKAI Sunter, dilakukan pada tanggal 18-20 Januari 2020. Sampel dalam catatan penelitian lapangan (CPL) yang digunakan sejumlah 7 orang pemuda. Jenis kelamin responden yakni pria dan wanita. Usia responden antara $16-23$ tahun.

\section{HASIL EKESEGESA 1TESALONIKA 4:1-8}

Hasil pembahasan berdasarkan 1Tesalonika 4:1-8 dijabarkan dengan menggunakan focus dan sub focus sesuai dengan tabel di bawah ini:

\begin{tabular}{|l|l|l|}
\hline Fokus & \multicolumn{1}{|c|}{ Sub fokus } & \multicolumn{1}{c|}{ Sub-sub fokus } \\
\hline & $\begin{array}{l}\text { Hidup yang berkenan } \\
\text { kepada Allah (ay. 1-3a) }\end{array}$ & $\begin{array}{l}\text { 1. Melakukan perintah Allah } \\
\text { dengan sungguh-sungguh } \\
\text { (ay.1-2) }\end{array}$ \\
& $\begin{array}{l}\text { 2. } \begin{array}{l}\text { Belajar tentang pengajaran } \\
\text { kekudusan yang benar (ay. } \\
3 \text { a) }\end{array} \\
\end{array}$ \\
& \\
& \\
&
\end{tabular}

\footnotetext{
${ }^{5}$ Andreas Bambang Subagyo, Pengantar Riset Kuantitatif Dan Kualitatif (Bandung: Kalam Hidup, 2004), 140-145.

${ }^{6}$ Stevri I.Lumintang, “Analisis Peningkatan Mutu Manajemen Perguruan Tinggi Keagamaan Berhaluan Injili dengan Menggunakan Ishikawa Fishbone Diagram: Penelitian di Institut Injil Indonesia.” Disertasi (Jakarta: Program Pascasarjana Universitas Negeri Jakarta, 2012), 128.

${ }^{7}$ Lexy J. Moleong, Metodologi Penelitian Kualitatif (Bandung: PT. Remaja Rosdakarya, 2013), 229.
} 


\begin{tabular}{|c|c|c|}
\hline \multirow[t]{2}{*}{$\begin{array}{l}\text { Kekudusan Menurut } \\
\text { 1Tesalonika 4:1-8 }\end{array}$} & $\begin{array}{l}\text { Hidup dalam kekudusan } \\
\text { (ay. 3b-5) }\end{array}$ & $\begin{array}{ll}\text { 1. } & \text { Menjauhi percabulan (ay. } \\
\text { 3) } \\
\text { 2. Hidup dalam pernikahan } \\
\text { yang dikehendaki Allah } \\
\text { (ay. 4a) } \\
\text { 3. Tidak menuruti hawa nafsu } \\
\text { (ay. 5) }\end{array}$ \\
\hline & $\begin{array}{l}\text { Hidup melakukan } \\
\text { kehendak Tuhan (ay. 6-8) }\end{array}$ & $\begin{array}{l}\text { 1. Tidak melakukan apa yang } \\
\text { cemar (ay.7a) } \\
\text { 2. Melakukan apa yang kudus } \\
\text { (ay.7b) } \\
\text { 3. Hidup dalam Roh-Nya } \\
\text { yang kudus (ay.8) }\end{array}$ \\
\hline
\end{tabular}

Tabel 1. Fokus dan Sub Fokus

\section{Hidup yang Berkenan kepada Allah (1Tes. 4: 1-3a)}

1Tesalonika. 4:1 berkata "Akhirnya, saudara-saudara, kami minta dan nasihatkan kamu dalam Tuhan Yesus: kamu telah mendengar dari kami bagaimana kamu harus hidup supaya berkenan kepada Allah. Hal ini memang telah kamu turuti, tetapi baiklah kamu melakukannya lebih bersungguh-sungguh lagi" dalam Bahasa Yunani ialah " $\Lambda$ oıtov ovv, $\alpha \delta \varepsilon \lambda \phi o r, ~ \varepsilon \rho \omega \tau \omega \mu \varepsilon v ~ v \mu \alpha \zeta \kappa \alpha \imath$

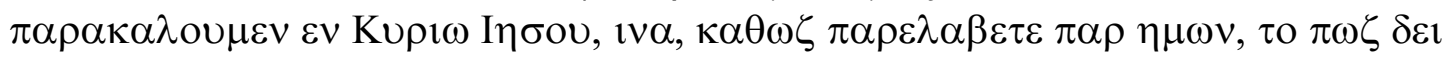

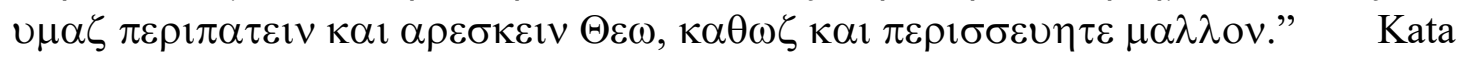
yang digunakan dalam bahasa Yunani "kami menasihatkan" adalah $\pi \alpha \rho \alpha \kappa \alpha \lambda$ ou $\mu \varepsilon v$ (parakaloumen) $\pi \alpha \rho \alpha \kappa \alpha \lambda \varepsilon \omega=$ Verb, present, Indicative, Active, 1st, Person, Plural. (kata kerja, menyajikan, indikatif, aktif, orang pertama, jamak) arti dari kata ini adalah memanggil datang, mengajak, mengundang, berseru, minta tolong, memohon, mendesak, menasihati, menghibur, memberi dorongan, berbicara dengan ramah. ${ }^{8}$ Berdasarkan konteks, hidup yang berkenan kepada Allah yaitu melakukan perintah Allah dengan sungguh-sungguh termasuk diantaranya adalah menjaga kekudusan.

\section{Hidup dalam kekudusan (1Tesalonika 4:3b-5)}

Allah menghendaki umat-Nya agar melakukan semua perintah-Nya. mengatakan "jangan berzinah" (Keluaran 20:14). Allah Ia menginginkan agar orang percaya mengikuti kehendak-Nya, menjauhi percabulan., kata "percabulan" dalam bahasa aslinya memakai kata " $\pi$ o $\rho v \varepsilon i \alpha \zeta "$ (porneias) akar kata dari " $\pi$ o $\rho v \varepsilon 1 \alpha "$ (porneia) yang berarti perzianaan. " $\operatorname{co\rho v\varepsilon } \_\alpha \zeta$ " (porneias) Noun, Feminime, Singular, Genetive. $^{9}$

Hidup dalam kekudusan juga dimaknai dalam konsep pernikahan yang sebagai suami istri. Pernikahan hubungan pria dan wanita yang dipersatukan oleh Allah dalam sebuah pernikahan dan menjai suami istri. Pernikahan Kristen bersifat monogami, terdiri dari hanya satu suami dan satu istri. Pernikahan Kristen tidak ada yang dapat memisahkan. Pernikahan Kristen didasarkan atas Allah sebagai sumber cinta sehingga manusia hidup dalam cinta seperti Allah. Karena itu setiap orang

\footnotetext{
${ }^{8}$ Perjanjian Baru Interlinear Yunani-Indonesia dan Konkordansi Perjanjian Baru (PBIK) Jilid II, Penyunting: Hasan Sutanto (Jakarta: Lembaga Alkitab Indonesia, 2006), 282.

${ }^{9}$ Ibid., 662.
} 
Kristen harus hidup dalam kasih. ${ }^{10}$ Apa yang telah dipersatukan oleh Allah tidak dapat diceraikan oleh manusia.

Hidup dalam kekudusan berarti juga tidak menuruti hawa nafsu. Arti nafsu disini adalah kehendak dan pikiran manusia yang terpikat kepada dunia., "hawa nafsu" memakai kata " $\pi \alpha \theta \varepsilon$ " (pathei) akar kata dari " $\pi \alpha \theta o \zeta$ " (pathos) yang artinya hawa nafsu. " $\pi \alpha \theta \varepsilon$ " (pathei) Noun, Neuter, Singular, Dative. ${ }^{11}$ Demikianlah keadaan manusia ketika belum lahir baru akan mudah terpengaruh oleh hal-hal duniawi dan tidak bisa mengendalikan nafsu diri sendiri. Karena itu Rasul Paulus memberikan nasihat kepada orang-orang di Tesalonika agar tidak hidup dalam hawa nafsu seperti orang-orang yang tidak mengenal Allah.

\section{Hidup melakukan kehendak Tuhan (1Tesalonika 4:6-8)}

Hidup melakukan kehendak Tuhan dijelaskan dengan tidak melakukan apa yang cemar (ay. 7a). Arti kata "cemar" adalah kotor, ternoda, keji, cabul, mesum, buruk dan tercela. Perbuatan dan Allah sendiri tidak menginginkan anak-anak-Nya jatuh dalam dosa ini, karena Allah telah memanggil orang percaya untuk hidup di dalam Dia. ${ }^{12}$ Dalam bahasa aslinya kata "cemar" memakai kata " $\alpha \kappa \alpha \theta \alpha \rho \sigma 1 \alpha$ " (akatharsia) akar kata dari " $\alpha \kappa \alpha \theta \alpha \rho \sigma \iota \alpha$ ” (akatharsia) yang berarti kotoran, hal tidak bermoral. " $\alpha \kappa \alpha \theta \alpha \rho \sigma \iota \alpha$ " (akatharsia) Noun, Feminime, Singular, Dative. Kata ini muncul dalam Alkitab sebanyak 10 kali. Ketika seseorang telah dipanggil Tuhan maka harus hidup dengan tidak melakukan kenajisan, fisik dan moral yang tidak jelas. Inilah yang dimaksud oleh Rasul Paulus apa artinya tidak melakukan apa yang cemar.

Berikutnya adalah melakukan apa yang kudus (ay. 7b). Kata kudus, ialah

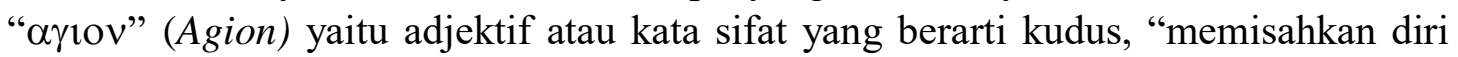
dari dunia dan dijauhkan dari dosa supaya kita mempunyai persekutuan yang erat dengan Allah dan melayani Dia dengan sukacita." Arti kata "kudus" adalah segala sesuatu yang terpisahkan dari kebiasaan atau hal-hal yang duniawi, dalam bahasa aslinya kata "kudus" memakai kata " $\alpha \gamma(\alpha \sigma \mu \omega "$ (hagiasmo) akar kata dari " $\alpha \gamma 1 \alpha \sigma \mu \omega \zeta "$ (hagiasmos) yang berarti pengudusan, penahbisan, kehidupan kudus. " $\alpha \gamma 1 \alpha \sigma \mu \omega$ " (hagiasmo) Noun, Masculine, Singular, Dative. ${ }^{13}$ Kata ini muncul dalam Alkitab sebanyak 10 kali. Paulus memberikan nasihat kepada jemaat di Tesalonika agar melakukan apa yang kudus dihadapan Allah, karena Allah sendiri adalah kudus. Kekudusan adalah sesuatu yang harus dikerjakan terus menerus, dalam proses dan usaha yang tidak berhenti.

Hidup dalam Roh-Nya yang kudus (ay.8). Roh memberikan karunia-karunia yang beraneka ragam (1Kor. 12:4) untuk membangun kehidupan gereja. Roh juga menyatakan kebenaran-kebenaran baru kepada setiap generasi (Yoh. 14:26), dan oleh Roh orang percaya mengenali Yesus (1Kor. 12:3) dan mengikuti teladan-Nya (2Kor. $3: 18$ ). Dalam bahasa aslinya kata "Roh" memakai kata " $\pi v \varepsilon v \mu \alpha "$ (pneuma) akar kata dari " $\pi v \varepsilon v \mu \alpha "$ (pneuma) yang berarti napas, angin, Roh, sikap. " $\pi v \varepsilon v \mu \alpha "$ (pneuma) Noun, Neuter, Singular, Accusative. Kematian Yesus di kayu salib mengakibatkan hubungan manusia dengan Allah dipulihkan. Karena itu, waktu menyembah dalam roh dan kebenaran berarti kita dan seluruh totalitas hidup kita sedang memberi diri

\footnotetext{
${ }^{10}$ Stephen Tong, Keluarga Bahagia. (Surabaya: Momentum, 2012), 25

${ }^{11}$ Perjanjian Baru Interlinear, 662

${ }^{12}$ Geoffrey W. Bromiley, theology Dictonary New Testment

${ }^{13}$ Perjanjian Baru Interlinear
} 
untuk menyembah dalam pimpinan Roh Kudus. Jadi, Rasul Paulus mengatakan bahwa jikalau kita mau hidup di dalam Roh maka kita harus memiliki kehidupan, pikiran dan Roh yang suci agar hidup kita kudus dihadapan Allah.

\section{HASIL DAN PEMBAHASAN}

Ditinjau dari usia dan jenis kelamin koresponden maka dapat dipihat dalam table berikut:

\begin{tabular}{|l|l|l|}
\hline Usia & Jumlah & Persentase \\
\hline 16 & 1 & 14,3 \\
\hline 19 & 2 & 28,6 \\
\hline 20 & 1 & 14,3 \\
\hline 21 & 1 & 14,3 \\
\hline 23 & 2 & 28,6 \\
\hline
\end{tabular}

\begin{tabular}{|l|l|l|} 
Jenis Kelamin & Jumlah & Persentase \\
\hline Pria & 4 & 57,1 \\
\hline Wanita & 3 & 42,9 \\
\hline & & \\
\hline & & \\
\hline & & \\
\hline
\end{tabular}

Tabel 2. Koresponden

\section{Pemahaman Pemuda Terhadap Kekudusan Menurut 1Tesalonika 4:1-8}

Dengan analisa taksonomi Peneliti menemukan pemahaman pemuda GKAI Sunter dalam kekudusan sebagai berikut:

\begin{tabular}{|l|l|l|}
\hline \multirow{2}{*}{ CPL } & \multicolumn{2}{c|}{ Hidup Berkenan Kepada Allah } \\
\cline { 2 - 3 } & Cara hidup berkenan kepada Allah & \multicolumn{1}{c|}{ Alasan menjaga kekudusan } \\
\hline 1 & Bertobat & Menjaga kekudusan hidup \\
\hline 2 & $\begin{array}{l}\text { Hidup dalam kekudusan dan } \\
\text { mentaati perintah Tuhan }\end{array}$ & Supaya hidup berkenan kepada Allah \\
\hline 3 & Hidup dalam kekudusan & Agar menjaga kita dari dosa \\
\hline 4 & Melakukan petunjuk-petunjuknya & Agar kita layak di hadapan Tuhan \\
\hline 5 & Hidup kudus & Supaya layak dan dapat dipakai Tuhan \\
\hline 6 & Menjadi serupa dengan Allah & Agar hidup sesuai dengan firman Allah \\
\hline 7 & Hidup kudus & Agar berkenan kepada Allah \\
\hline
\end{tabular}

Tabel 3. Sub Fokus 1

Jawaban di atas menjunjukkan bahwa pemuda GKAI Sunter memiliki pemahaman yang baik tentang hidup berkenan kepada Allah.

\begin{tabular}{|l|l|l|l|l|}
\hline \multirow{2}{*}{ CPL } & \multicolumn{3}{|c|}{ Hidup dalam Kekudusan } \\
\cline { 2 - 5 } & \multicolumn{1}{|c|}{ Jenis percabulan } & $\begin{array}{c}\text { Mengapa harus } \\
\text { dijauhi }\end{array}$ & $\begin{array}{c}\text { Sifat Pernikahan } \\
\text { Kristen }\end{array}$ & Bolehkah bercerai \\
\hline 1 & $\begin{array}{l}\text { Sex sebelum } \\
\text { menikah, } \\
\text { pemerkosaan, } \\
\text { pembunuhan }\end{array}$ & $\begin{array}{l}\text { Tidak berkenan } \\
\text { kepada Tuhan }\end{array}$ & Monogami & $\begin{array}{l}\text { Tidak. Karena } \\
\text { sudah dipersatukan } \\
\text { oleh Tuhan }\end{array}$ \\
\hline 2 & $\begin{array}{l}\text { Seks di luar } \\
\text { pernikahan }\end{array}$ & Kita adalah kudus & Monogami & $\begin{array}{l}\text { Tidak. Kita telah } \\
\text { berjanji di hadapan }\end{array}$ \\
\hline
\end{tabular}


Jurnal Teologi Biblika, Vol. 5, No. 1, Edisi April 2020

Enny Irawati, Kekudusan Hidup Menurut 1Tesalonika 4:1-8 Relevansinya Terhadap Pemahaman

Pemuda di GKAI Sunter,

\begin{tabular}{|l|l|l|l|l|}
\hline & \multicolumn{2}{|c|}{ Hal: 3-12 } \\
\hline 3 & $\begin{array}{l}\text { Kata-kata kotor, } \\
\text { pemerkosaan, sex di } \\
\text { luar pernikahan }\end{array}$ & Karena dosa & Monogami & $\begin{array}{l}\text { Tuhan } \\
\text { Tidak. Firman melarang } \\
\text { perceraian }\end{array}$ \\
\hline 4 & $\begin{array}{l}\text { Menuruti hawa } \\
\text { nafsu }\end{array}$ & Kita harus kudus & Monogami & $\begin{array}{l}\text { Tidak. Sudah } \\
\text { dipersatukan }\end{array}$ \\
\hline 5 & $\begin{array}{l}\text { Pemerkosaan, sex di } \\
\text { luar pernikahan }\end{array}$ & $\begin{array}{l}\text { Supaya berkenan } \\
\text { kepada Allah }\end{array}$ & Monogami & $\begin{array}{l}\text { Tidak. Tuhan } \\
\text { melarang karena } \\
\text { sudah dipersatukan }\end{array}$ \\
\hline 6 & $\begin{array}{l}\text { Tidak dapat } \\
\text { menahan nafsu } \\
\text { dunia }\end{array}$ & $\begin{array}{l}\text { Kita adalah Bait } \\
\text { Allah }\end{array}$ & Monogami & $\begin{array}{l}\text { Tidak. Sudah } \\
\text { dipersatukan }\end{array}$ \\
\hline 7 & $\begin{array}{l}\text { Sex di luar } \\
\text { pernikahan }\end{array}$ & Itu dosa & Monogami & $\begin{array}{l}\text { Tidak. Dilarang } \\
\text { oleh Tuhan }\end{array}$ \\
\hline
\end{tabular}

Tabel 4. Sub Fokus 2

Jawaban di atas menjunjukkan bahwa pemuda GKAI Sunter memiliki pemahaman yang cukup baik tentang hidup dalam kekudusan bahwa tidak boleh melakukan seks di luar pernikahan dan pernikahan yang bersifat monogami dan tidak boleh bercerai.

\begin{tabular}{|l|l|l|}
\hline \multirow{2}{*}{} & \multicolumn{2}{|c|}{ Hidup melakukan kehendak Tuhan } \\
\cline { 2 - 3 } & \multicolumn{1}{|c|}{$\begin{array}{c}\text { Hidup dalam Roh dan menjauhi } \\
\text { hawa nafsu }\end{array}$} & \multicolumn{1}{c|}{ Siapakah Roh Kudus } \\
\hline 1 & Tidak mudah tergoda & Penolong \\
\hline 2 & Menjauhi pemikiran seksual & Pribadi Allah Tritunggal \\
\hline 3 & Menjauhi keinginan daging & Penolong yang memimpin kita \\
\hline 4 & Tidak melakukan percabulan & Pengampunan, kesabaran \\
\hline 5 & Tidak menuruti daging & $\begin{array}{l}\text { Pribadi Allah Tritunggal yang menolong } \\
\text { kita }\end{array}$ \\
\hline 6 & Tidak menuruti hawa nafsu & $\begin{array}{l}\text { Roh yang ada dalam hidup kita yang } \\
\text { paling besar daripada roh-roh lainnya }\end{array}$ \\
\hline 7 & Menjauhi kedagingan & Roh yang asalnya dari Tuhan \\
\hline
\end{tabular}

Tabel 5. Sub Fokus 3

Jawaban di atas menjunjukkan bahwa pemuda GKAI Sunter memiliki pemahaman yang baik tentang hidup melakukan kehendak Tuhan.

\section{Analisa Hasil Pemahaman Pemuda GKAI Sunter tentang Kekudusan}

Sub Fokus 1. Hidup Berkenan Kepada Allah

Dari analisa pemahaman pemuda dalam hidup berkenan kepada Allah diperoleh hasil sebagai berikut:

\begin{tabular}{|l|l|}
\hline \multicolumn{1}{|c|}{ Analisa pemahaman cara hidup berkenan kepada Allah } & \multicolumn{1}{c|}{$\begin{array}{c}\text { Prosentas pemahaman } \\
\text { pemuda }\end{array}$} \\
\hline Bertobat & $10 \%$ \\
\hline Meminta ampun & $10 \%$ \\
\hline Melakukan kehendak Allah & $40 \%$ \\
\hline Hidup dalam kekudusan & $40 \%$ \\
\hline
\end{tabular}

Tabel 6. Analisa Hidup berkenan kepada Allah 
Dari tabel di atas ditemukan sebagian besar pemuda yaitu 40 persen mengatakan bahwa cara hidup berkenan kepada Allah dalam Kekudusan Menurut 1Tesalonika 4:1-8 adalah Hidup dalam kekudusan dan 40 persen mengatakan melakukan kehendak Allah. Hanya Sebagian kecil masing-masing 10 persen yang menjawab tidak sesuai dengan Analisa eksegesa 1 Tesalonika 4:1-8.

\begin{tabular}{|l|l|}
\hline \multicolumn{1}{|c|}{$\begin{array}{c}\text { Analisa pemahaman hubungan menjaga kekudusan dengan } \\
\text { hidup berkenan kepada Allah }\end{array}$} & $\begin{array}{c}\text { Prosentas pemahaman } \\
\text { pemuda }\end{array}$ \\
\hline Menjaga kekudusan & $14,2 \%$ \\
\hline Menjaga kekudusan agar hidup berkenan kepada Allah & $57,4 \%$ \\
\hline Menjaga kita dari dosa & $14,2 \%$ \\
\hline Hidup sesuai firman Allah & $14,2 \%$ \\
\hline
\end{tabular}

Tabel 7. Analisa Hidup berkenan kepada Allah

Dari tabel di atas ditemukan sebagian besar pemuda yaitu 57,2 persen mengatakan bahwa menjaga kekudusan erat kaitannya dengan berkenan kepada Allah. Agar hidup berkenan kepada Allah maka pemuda harus menjaga kekudusan. Pemahaman yang lain juga tidak jauh berbeda artinya dan saling mendukung antara pentingnya menjaga kekudusan dan berkenan kepada Allah.

Sub Fokus 2. Hidup dalam kekudusan

Dari analisa pemahaman pemuda hidup dalam kekudusan diperoleh hasil sebagai berikut:

\begin{tabular}{|l|l|}
\hline \multicolumn{1}{|c|}{ Jenis percabukan yang harus dijauhi } & \multicolumn{1}{c|}{ Prosentas pemahaman pemuda } \\
\hline Sex sebelum menikah & $41,6 \%$ \\
\hline Pemerkosaan & $25 \%$ \\
\hline Pembunuhan & $8,3 \%$ \\
\hline Kata-kata kotor & $8,3 \%$ \\
\hline Hawa nafsu & $16,6 \%$ \\
\hline
\end{tabular}

Tabel 8. Analisa Hidup dalam kekudusan

Dari tabel di atas ditemukan sebagian besar pemuda yaitu 41,6 persen mengatakan bahwa hidup dalam kekudusan berarti tidak boleh melakukan hubungan sezx sebelum menikah. Hanya Sebagian kecil masing-masing 8,3 persen yang menjawab tidak sesuai dengan Analisa eksegesa 1 Tesalonika 4:1-8.

\begin{tabular}{|l|l|}
\hline \multicolumn{1}{|c|}{ Sifat dalam pernikahan Kristen } & Prosentas pemahaman pemuda \\
\hline Monogami & $100 \%$ \\
\hline
\end{tabular}

Tabel 9. Analisa sifat pernikahan Kristen

Dari tabel di atas ditemukan semua pemuda mengatakan bahwa pernikahan Kristen bersifat monogam.

\begin{tabular}{|l|l|}
\hline \multicolumn{1}{|c|}{ Bolehkah Bercerai dalam pernikahan Kristen } & Prosentas pemahaman pemuda \\
\hline Tidak boleh bercerai & $100 \%$ \\
\hline
\end{tabular}

Tabel 10. Analisa perceraian dalam pernikahan Kristen

Dari table di atas ditemukan semua pemuda mengatakan bahwa dalam pernikahan tidak diperbolehkan adanya perceraian. 
Sub Fokus3. Hidup melakukan kehendak Tuhan

Dari analisa pemahaman pemuda hidup dalam hidup melakukan kehendak Tuhandiperoleh hasil sebagai berikut:

\begin{tabular}{|l|l|}
\hline \multicolumn{1}{|c|}{ Cara melakukan kehendak Tuhan } & Prosentas pemahaman pemuda \\
\hline Tidak mudah tergoda & $14,3 \%$ \\
\hline Menjauhi pemikiran seksual & $14,3 \%$ \\
\hline Menjauhi keinginan daging & $42,8 \%$ \\
\hline Tidak melakukan percabulan & $14,3 \%$ \\
\hline Menahan hawa nafsu & $14,3 \%$ \\
\hline
\end{tabular}

Tabel 11. Analisa cara melakukan kehendak Tuhan

Dari tabel di atas ditemukan sebagian besar pemuda yaitu 42,8 persen mengatakan bahwa melakukan kehendak Tuhan adalah dengan menjauhi keinginan daging. Tetapi definisi menjauhi keinginan daging belum memiliki arti yang jelas. Pemahaman yang sangat terukur sebesar 14,3 persen yang mengatakan bahwa cara nelakukan kehendak Tuhan dalam menjaga kekudusan adalah menjauhi pemikiran seksual. Pemahaman yang lain juga pada dasrnya tidak jauh berbeda artinya dan saling mendukung tentang cara melakukan kehendak Tuhan.

\section{SIMPULAN}

Pemuda GKAI Sunter memiliki pemahaman yang pemahaman yang baik tentang kekudusan menurut 1Tesalonika 4:1-8. Pemahaman yang paling tinggi adalah bahwa dalam pernikahan Kristen bersifat monogami dan tidak boleh ada perceraian, dilanjutkan dengan pemahaman bahwa menjaga kekudusan berarti tidak boleh melakukan seks di luar penikahan dan yang paling rendah adalah pemahaman tentang jenis percabulan yang harus dijauhi yaitu pembunuhan dan kata-kata kotor.

\section{DAFTAR PUSTAKA}

Alkitab. Jakarta: Lembaga Alkitab Indonesia. 2009.

Andreas Bambang Subagyo, Pengantar Riset Kuantitatif Dan Kualitatif. Bandung: Kalam Hidup, 2004.

Ariotang, S Jan. Berbagai Aliran di Dalam dan Disekitar Gereja. Jakarta:BPK. Gunung Mulia, 1995.

Berkhof. Louis. Theologi Sitematika. Jakarta: Lembaga Informed Injili Indonesia, 1996.

Browning. W.R.F. Kamus Alkitab Jakarta: BPK Gunung Mulia, 2007.

Bromiley W. Geoffrey, theology Dictonary New Testment.

Irawati, Enny. Problema Pemuda Memasuki Jenjang Pernikahan. Jakarta: STT Biblika Jakarta, 2015.

J. Wesley Brill. Doa-Doa dalam Perjanjian Baru. Bandung: Penerbit Kalam Hidup, 23.

Lexy J. Moleong, Metodologi Penelitian Kualitatif. Bandung: PT. Remaja Rosdakarya, 2013.

Lumintang, L. Stevri. Disertasi. Jakarta: Program Pascasarjana Universitas Negeri Jakarta, 2012.

Matukupan, J. Thomy dan Julio Kristanto, Doktrin Manusia dan Dosa. Surabaya: Penerbit Momentum, 2010. 
Mc Grath, Alister E. Sejarah Pemikiran Reformasi. Jakarta: BPK. Gunung Mulia, 2000.

Perjanjian Baru Interlinear Yunani-Indonesia dan Konkordansi Perjanjian Baru $(P B I K)$ Jilid II, Penyunting: Hasan Sutanto. Jakarta: Lembaga Alkitab Indonesia, 2006.

Robert, D Mecroskey. Theologia Sistematika dari Sudut Pandang Wesley-Arminion. Yogyakarta: Khabar Kekudusan, 2004.

Tong, Stephem. Keluarga Bahagia. Surabaya: Momentum, 2012.

Verkuyl. J. Etika Kristen. Jakarta: BPK Gunung Mulia, 2007.

Koresponden 1. Alfionata Ambeua, 23 tahun.

Koresponden 2. Berkat Harefa, 19 tahun.

Koresponden 3. Hiri, 23 tahun.

Koresponden 4. Melni Hulu, 19 tahun.

Koresponden 5. Apel Hulu, 21 tahun.

Koresponden 6. Devan Setya Putra, 20 tahun.

Koresponden 7. Karin Klarisa Putri, 16 tahun. 